\title{
Osteoblastoma of C2 Corpus: 4 Years Follow-up
}

\author{
Cem Yilmaz ${ }^{1}$, Erdinc Civelek ${ }^{1}$, Hakan Caner $^{1}$, Erdinc Aydin $^{2}$, Aydin Gerilmez $^{1}$, Nur Altinors ${ }^{1}$ \\ ${ }^{1}$ Department of Neurosurgery, Baskent University School of Medicine, Ankara, Turkey \\ ${ }^{2}$ Department Otorhino-laryngology, Baskent University School of Medicine, Ankara, Turkey
}

\begin{abstract}
Osteoblastomas are rare neoplasms of the spine. The majority of the spinal lesions arise from the posterior elements and involvement of the corpus is usually by extension through the pedicles. An extremely rare case of isolated C2 corpus osteoblastoma is presented herein. A 9-year-old boy who presented with neck pain and spasmodic torticollis was shown to have a lesion within the corpus of $\mathrm{C} 2$. He underwent surgery via an anterior cervical approach and the completely-resected mass was reported to be an osteoblastoma. The pain resolved immediately after surgery and he had radiologic assessments on a yearly basis. He was symptom-free 4 years post-operatively with benign radiologic findings. Although rare, an osteoblastoma should be considered in the differential diagnosis of neck pain and torticollis, especially in patients during the first two decades of life. The standard treatment for osteoblastomas is radical surgical excision because the recurrence rate is high following incomplete resection.
\end{abstract}

Key Words: Osteoblastoma, Osteoid osteoma, C2 corpus, Anterior cervical approach

\section{Introduction}

An osteoblastoma is a rare, benign, bone neoplasm that represents approximately $1 \%$ of primary bone neoplasms $[1,2]$. An osteoblastoma has a male-to-female ratio of 2:1 and occurs primarily in the first 2 decades of life [1,2]. Osteoblastomas are similar to osteoid osteomas histologically and clinically, but some characteristic differences do exist. The nidus characteristics of osteoid osteomas and osteoblastomas are different; osteoblastomas tend to form less sclerotic, but more expansible masses [3]. Also, osteoblastomas are larger, have greater growth potential with the ability of malignant transformation, and tend to cause more neurologic symptoms when located to the spine [2-4].

Greater than one-third of osteoblastomas (35\% to $40 \%)$ arise from the spine and are generally from the posterior elements of the vertebra; involvement of the corpus is usually via extension through the pedicles $[1,5,6]$. An isolated $\mathrm{C} 2$ corpus osteoblastoma is extremely rare.

\section{Case Report}

A 9-year-old boy was admitted with a 1-year history of neck pain. The pain was progressive, not relieved with medical treatment, and was causing restriction of neck movement for 2 months. The examination revealed a spasmodic torticollis which was present for 1 week. There was no history of trauma. The neurologic examination was normal. Cervical magnetic resonance imaging revealed a $13 \times 12 \times 15 \mathrm{~mm}$ mass causing erosion of the $\mathrm{C} 2$ corpus. The mass was slightly hypointense on T1- and isointense on T2-weighted images. Following intravenous gadolinium injection, the mass and anterior epidural soft tissue enhanced homogeneously (Fig. 1). Computerized tomography (CT) revealed a 15-mm lesion lytic in the corpus of C2 (Fig. 2).

The patient underwent surgery via an anterior approach. A 4-cm skin incision was made in the left submandibular area. After sharp dissection of the skin, subcutaneous tissues, and platysma muscle, the facial vein and marginal mandibu-

Received Jan 15, 2011; Revised Apr 27, 2011; Accepted May 3, 2011

Corresponding author: Erdinc Civelek, MD

Department of Neurosurgery, Baskent University Istanbul Hospital,

Oymaci sok, No 7, Altunizade, Istanbul, Turkey

Tel: +90-216-554-1500, Fax: +90-216-651-9858, E-mail: civsurgeon@yahoo.com

Copyright (C) 2012 by Korean Society of Spine Surgery

This is an Open Access article distributed under the terms of the Creative Commons Attribution Non-Commercial License (http://creativecommons.org/licenses/by-nc/3.0/) which permits unrestricted non-commercial use, distribution, and reproduction in any medium, provided the original work is properly cited. Asian Spine Journal • pISSN 1976-1902 eISSN 1976-7846 
lar nerve were identified. The submandibular gland was retracted superiorly. The jugular vein, carotid artery, and vagus nerve were identified and retracted laterally. Medial to the nerve-vessel pack and below the hypoglossal nerve, the dissection was continued to the deep layer of the deep neck fascia. The deep neck fascia, prevertebral muscles, and prevertebral fascia were bluntly dissected and retracted. The $\mathrm{C} 2$ vertebral corpus was clearly visualized and wide enough to reach for a microsurgical approach. The cortex of $\mathrm{C} 2$ was removed using a high-speed bone drill. The mass was excised totally using curettes and forceps. Because bone drilling was limited and none of the structures contributing to the stability were damaged, a fusion was not performed.

The postoperative period was uneventful and the cervical pain resolved immediately post-operatively. The histopathologic examination revealed an osteoblastoma with osteoblasts around osteoid anastomoses, giant cells, and vascular stroma (Fig. 3). The patient had radiologic assessments on a yearly basis. At the 4-year follow-up examination, the patient was symptom-free and the CT revealed sclerosis of the corpus of $\mathrm{C} 2$ (Fig. 4).

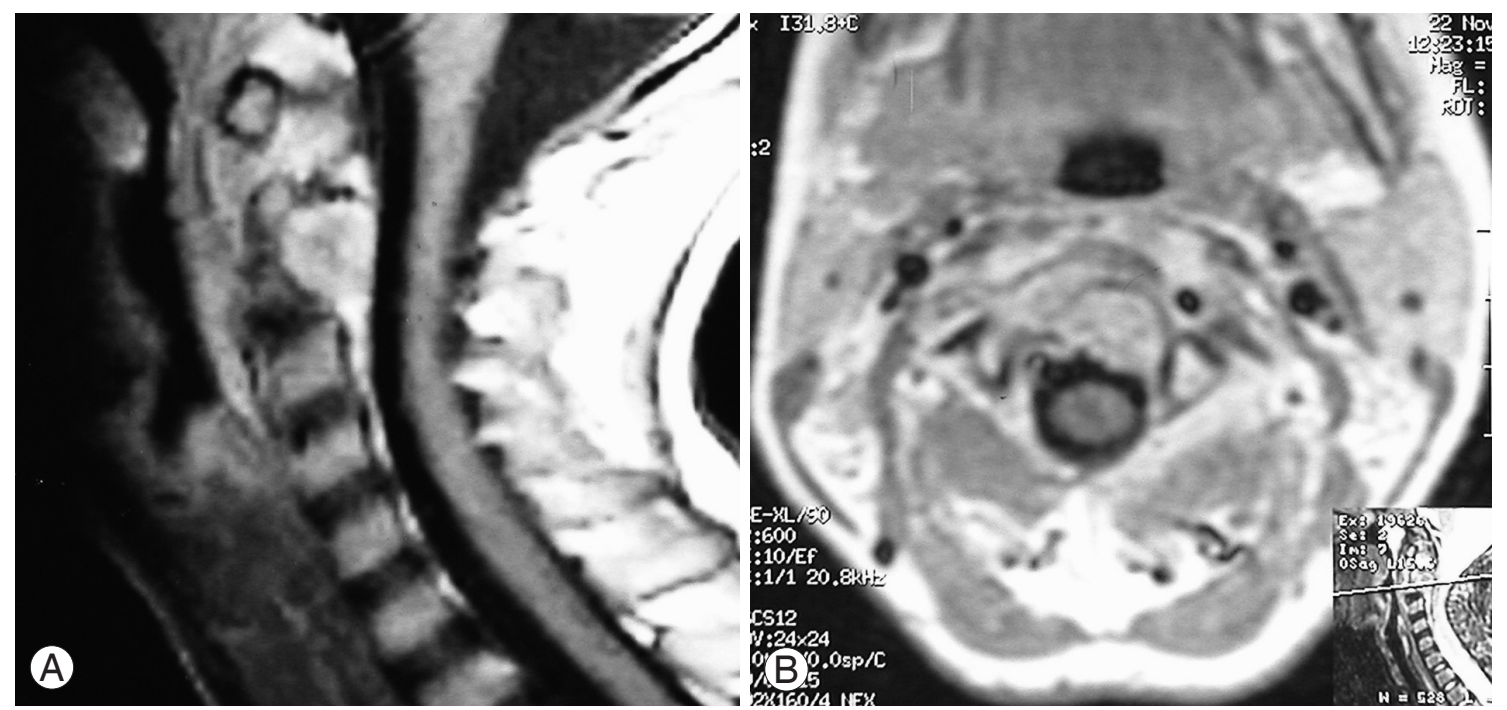

Fig. 1. Cervical magnetic resonance imaging revealed a $13 \times 12 \times 15 \mathrm{~mm}$ mass with homogeneous-enhanced anterior epidural soft tissues. (A) Sagittal post-contrast T1-weighted image. (B) Axial post-contrast T1-weighted image.

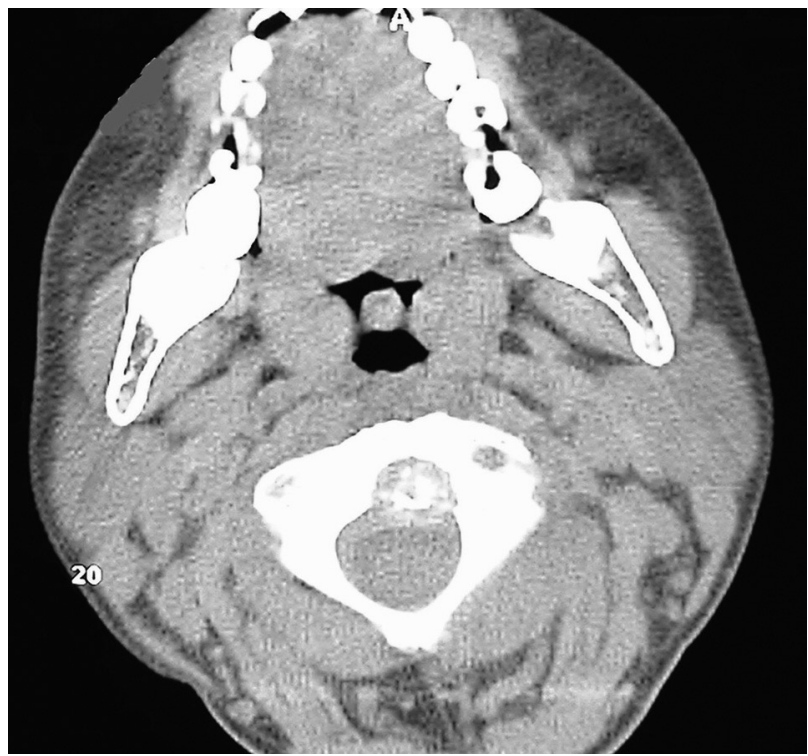

Fig. 2. Axial computerized tomography revealing a $15-\mathrm{mm}$ lytic lesion in the corpus of $\mathrm{C} 2$.

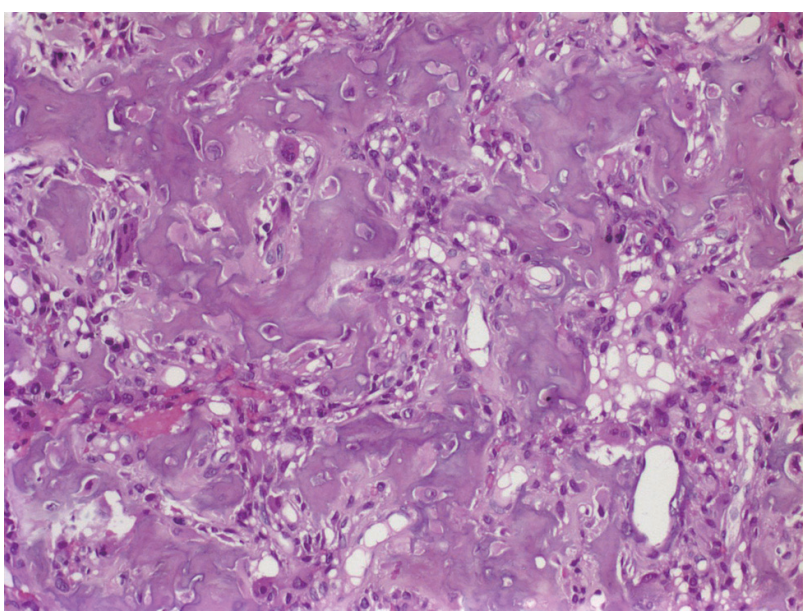

Fig. 3. Histopathology showing osteoblasts around osteoid anastomoses, giant cells, and vascular stroma. Irregular interlacing network of osteoids with prominent osteoblastic rimming is present. The osteoids are separated by fibrovascular stroma containing multinucleated osteoclast-like giant cells $(H \& E, \times 200)$. 

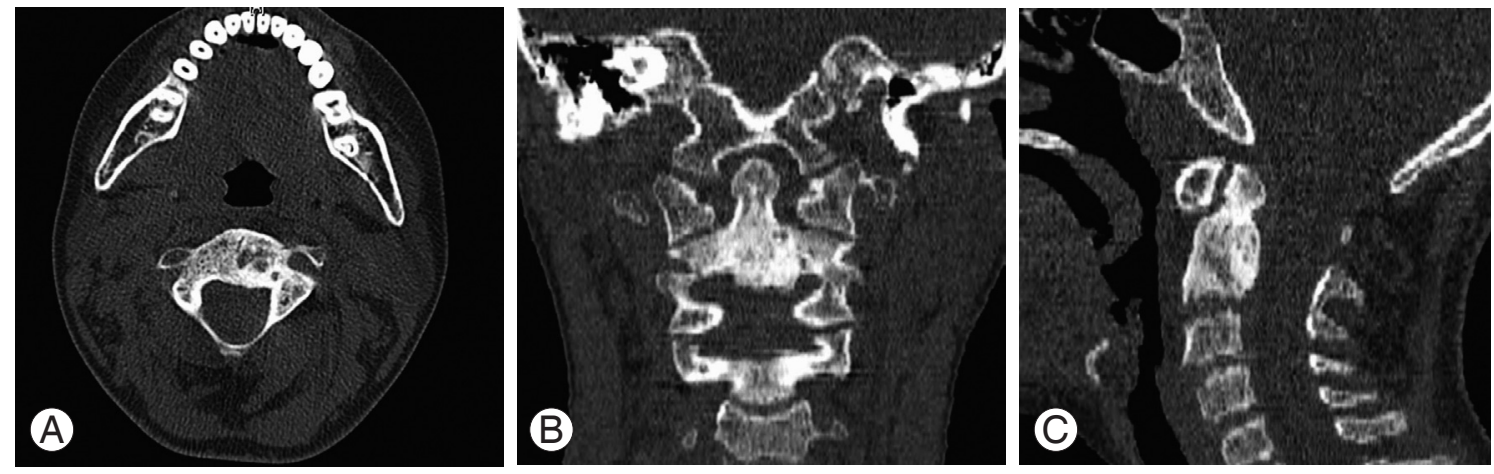

Fig. 4. Year 4 postoperative computed tomography showing sclerosis of the corpus of C2. (A) Axial image. (B) Coronal image. (C) Sagittal image.

\section{Discussion}

An osteoblastoma is a vascular, osteoid, bone-forming lesion located mostly in the long bones and posterior elements of the spine. Corpus involvement is rare and extension is usually through the pedicles. Isolated corpus osteoblastomas are very rare.

Only two cases of osteoblastomas of the C2 corpus have been reported [7,8]. Two other reports of osteoblastomas of the $\mathrm{C} 2$ odontoid process have been reported, and a histologically-similar lesion (osteoid osteoma) has also been reported to occur in the $\mathrm{C} 2$ corpus in several case reports $[5,6,9]$.

In the case reported by Camitta et al. [8], the surgical excision was incomplete, which inevitably led to a recurrence. The recurrent lesion was treated with chemotherapy consisting of methotrexate, doxorubicin, and cisplatin.

Local recurrences have been reported in $9.8 \%$ to $15 \%$ in other series of spinal osteoblastomas $[3,4,7]$. The main reason for this high rate of recurrence has been as attributed to incomplete resections. To avoid recurrences, meticulous and safe tumor curettage should be the primary goal of surgery. Considering the highly vascular nature of osteoblastomas, some authors have recommended pre-operative embolization to enhance visualization, while other authors obtain multiple biopsies to determine the exact extension of the tumor [2,5]. Another characteristic of osteoblastomas that can impair complete resection is the frequent association of epidural invasion with osteoblastomas, which causes a higher incidence of torticollis with cervical lesions, as reported by Raskas et al. [10]. Our case also had torticollis and epidural invasion was present, but we did not perform pre-operative embolization or obtain biopsies to determine the extent of the tumor. We suggest that visualization of the intra- operative surgical field is a determining factor for complete resection and the choice of surgical route is thus important.

We used an upward extension of the classical anterior cervical route for accessing the body of $\mathrm{C} 2$. This approach provided us with good surgical visualization and we achieved a complete resection. The transoral route is another way to reach $\mathrm{C} 2$, has been used by many authors, and has been reported to provide a good and safe approach to $\mathrm{C} 1-\mathrm{C} 2$ in experienced hands [5,9].

Osteoblastomas can be locally aggressive with a high tendency for recurrence and metastasis. Osteoblastomas can even undergo malignant transformation to osteosarcomas, although this is rare $[3,8,9]$. Radiotherapy and chemotherapy can be used for osteoblastomas, but the potential risk of post-radiation sarcomas must be kept in mind.

\section{REFERENCES}

1. Orbay T, Ataoğlu O, Tali ET, Kaymaz M, Alp H. Vertebral osteoblastoma: are radiologic structural changes necessary for diagnosis? Surg Neurol 1999;51:426-9.

2. Samdani A, Torre-Healy A, Chou D, Cahill AM, Storm PB. Treatment of osteoblastoma at C7: a multidisciplinary approach. A case report and review of the literature. Eur Spine J 2009;18 Suppl 2:196-200.

3. Combalia Aleu A, Popescu D, Pomes J, Palacin A. Long-standing pain in a 25 -year-old patient with a nondiagnosed cervical osteoblastoma: a case report. Arch Orthop Trauma Surg 2008;128:567-71.

4. Ozaki T, Liljenqvist U, Hillmann A, et al. Osteoid osteoma and osteoblastoma of the spine: experiences with 22 patients. Clin Orthop Relat Res 2002;(397):394-402.

5. Mori Y, Takayasu M, Saito K, Seki Y, Shibuya M, Yoshida J. Benign osteoblastoma of the odontoid process 
of the axis: a case report. Surg Neurol 1998;49:274-7.

6. Tarantino R, Piccirilli M, Anichini G, Delfini R. Benign osteoblastoma of the odontoid process of the axis with secondary aneurysmal bone cyst component: a case report. Neurosurg Rev 2008;31:111-5.

7. Zileli M, Cagli S, Basdemir G, Ersahin Y. Osteoid osteomas and osteoblastomas of the spine. Neurosurg Focus 2003;15:E5.

8. Camitta B, Wells R, Segura A, Unni KK, Murray K,
Dunn D. Osteoblastoma response to chemotherapy. Cancer 1991;68:999-1003.

9. Arvin B, Panchmatia JR, Casey AT. Cervical C2 osteoma, unusual presentation and transoral approach for complete excision. Spine J 2009;9:e9-11.

10. Raskas DS, Graziano GP, Herzenberg JE, Heidelberger $\mathrm{KP}$, Hensinger RN. Osteoid osteoma and osteoblastoma of the spine. J Spinal Disord 1992;5:204-11. 